\title{
Management of chronic hepatitis B patients in immune- tolerant phase: what latest guidelines recommend
}

\author{
Grace Lai-Hung Wong ${ }^{1,2,3}$ \\ Institute of Digestive Disease, ${ }^{2}$ Department of Medicine and Therapeutics, and ${ }^{3}$ State Key Laboratory of Digestive Disease, The Chinese \\ University of Hong Kong; Hong Kong SAR, China
}

The natural history of chronic hepatitis B (CHB) is complex and may run through different immune phases that may overlap. In particulars, the immune-tolerant phase is the most interesting and not as well understood as we thought. The concept of true immune tolerance have been under challenged from immunology points of view. The major international guidelines have not yet reached a consensus on the definition of the immune-tolerant phase. While positive hepatitis B e antigen ( $\mathrm{HBeAg}$ ), high serum hepatitis B virus (HBV) DNA and normal serum alanine aminotransferase (ALT) levels are the three key features of this phase, some guidelines also put age into consideration. A new nomenclature, Phase 1 or HBeAg-positive chronic HBV infection, is given by the latest European Association for the Study of the Liver (EASL) published in April 2017. While current guidelines advise against starting antiviral treatment for immune-tolerant CHB patients, some new data suggest treating such patients may reduce the risk of liver fibrosis progression and hepatocellular carcinoma. (Clin Mol Hepatol 2018;24:108-113)

Keywords: Chronic hepatitis B; Hepatocellular carcinoma; Immune tolerance; Liver fibrosis; Positive HBeAg

\section{INTRODUCTION}

Chronic hepatitis B (CHB) is a life-threatening liver disease affecting 257 million people worldwide, in particular in the Asia-Pacific regions where the infection is endemic.' The natural history of $\mathrm{CHB}$, in particulars in patients infected via vertical transmission, is complex and may run through different immune phases that may overlap. Conventionally, the most commonly described four phases of CHB include immune-tolerant phase, immune clearance or active phase, inactive carrier phase and reactivation phase. ${ }^{2}$ Among these four phases, immune-tolerant phase is not as well understood and the concept of true immune tolerance have been under challenged. In this review, the latest knowledge on the definition, natural history and management recommended by latest international practice guidelines for patients in the immune-tolerant phase will be concisely discussed.

\section{DEFINITION OF IMMUNE-TOLERANT PHASE}

The major international guidelines have not yet reached a consensus on the definition of immune-tolerant phase. The latest guidelines published in 2016 by the American Association for the Study of Liver Diseases (AASLD) define immune-tolerant phase in

\footnotetext{
Abbreviations:

ALT,alanine aminotransferase; CHB, Chronic hepatitis B; HbeAg, hepatitis B e antigen; HBsAg, hepatitis B surface antigen; HBV, hepatitis B virus; HCC, hepatocellular carcinoma; MTCT, maternal-to-child transmission; TDF, tenofovir disoproxil fumarate; AASLD, the American Association for the Study of Liver Diseases; APASL, the Asian Pacific Association for the Study of the Liver; EASL, the European Association for the Study of the Liver; ULN, upper limit of normal; WHO, World Health Organization
}

\section{Corresponding author : Grace Lai-Hung Wong}

Department of Medicine and Therapeutics, 9/F Prince of Wales Hospital, 30-32 Ngan Shing Street, Shatin, Hong Kong

Tel: +852-3505-3996, Fax: +852-2637-3852

Email:wonglaihung@cuhk.edu.hk

https://orcid.org/0000-0002-2863-9389 
a more traditional way, i.e. normal alanine aminotransferase (ALT; $<30 \mathrm{U} / \mathrm{L}$ in men and $<19 \mathrm{U} / \mathrm{L}$ in women as upper limit of normal [ULN] rather than local laboratory reference ranges), elevated hepatitis B virus (HBV) DNA (typically above 1 million IU/mL), positive hepatitis $B$ e antigen ( $\mathrm{HBeAg}$ ), and minimal inflammation and fibrosis shown in liver histology. ${ }^{3}$ This is in contrast to another HBeAg-positive situation, the immune-active phase, with the key distinguish features of elevated serum ALT, high but perhaps not as high serum HBV DNA (>200,000 IU/mL) and moderate-to-severe inflammation or fibrosis shown in liver histology. ${ }^{3}$ On the other hand, the 2015 update of the practice guidelines of the Asian Pacific Association for the Study of the Liver (APASL) define immune-tolerant phase slightly differently from AASLD, mainly a different threshold of serum HBV DNA $(>20,000 \mathrm{IU} / \mathrm{mL})$, and putting up age as one of the criteria (typically below 30 years old). ${ }^{4}$

The concept of true immune tolerance have been challenged, as immunological studies revealed children and young adults with CHB have an immune profile that is less compromised than that observed in older patients. ${ }^{5}$ With these new observations, the newest international guidelines at the time of writing, the European Association for the Study of the Liver (EASL) practice guidelines published in April 2017, give this phase a new nomenclature - Phase 1 or HBeAg-positive chronic HBV infection - instead of the conventional immune-tolerant phase. ${ }^{6}$ The characteristics of this phase include what the AASLD guidelines describe, together with a few special features at the molecular and immunological levels namely high level of HBV DNA integration and clonal hepatocyte expansion, ${ }^{7}$ possible proceeding hepatocarcinogenesis, preserved HBV specific T cell function at least until young adulthood, very low rate of spontaneous HBeAg loss and highly contagious due to the high levels of HBV DNA. ${ }^{6}$

\section{NATURAL HISTORY OF CHB PATIENTS IN IMMUNE-TOLERANT PHASE}

\section{From immune-tolerance to $\mathrm{HBeAg}$ seroclearance / seroconversion}

An important Korean study recruited 133 children (mean age 10.6 years) with immune-tolerant CHB over more than 10 years reported that a low rate (1.7/100 patient-years) of conversion to early immune clearance phase. The estimated transition rate from immune tolerance to clearance increased dramatically with age: it was $4.6 \%, 7.1 \%$, and $28.0 \%$ for patients aged $6,6-12$, $>12$ years, respectively. ${ }^{8}$ Another Korean study of 90 adult $\mathrm{HBeAg} \mathrm{CHB}$ patients revealed spontaneous HBeAg seroconversion in patients with HBeAg-positive CHB was rare (1/90; 1.6\%) within 6 months; in contrast biochemical deterioration occurred up to $18.9 \% .{ }^{9}$ But this may be different from other parts of the world as Korea is one of the endemic areas of genotype C HBV infection, which is wellknown to be associated with delayed HBeAg seroconversion. ${ }^{10,11}$ In a study of 240 Taiwanese CHB patients (of genotype B and C HBV) who were HBeAg positive and normal ALT at baseline, 85\% patients had spontaneous HBeAg seroconversion at age 15 to 39 years. ${ }^{12}$

\section{Liver fibrosis progression}

The Taiwanese study described previously showed a small yet non-negligible risk of progression from immune-tolerant phase liver cirrhosis, which occurred in 13 patients (5.4\%) after a median follow-up of 10.5 years. ${ }^{12}$ The key risk factors included older age of HBeAg seroconversion and hepatitis relapse associated. ${ }^{12} \mathrm{~A}$ small retrospective histological series of 40 immune-tolerant CHB patients showed $50 \%$ of them had no fibrosis at all; while the other $50 \%$ had only F1 fibrosis. ${ }^{13}$ This implies liver fibrosis progression is uncommon in immune-tolerant CHB patients.

Subsequently another Hong Kong study involved 453 Chinese HBeAg-positive patients revealed that age $>35$ years and highnormal ALT>0.5XULN predicted advanced liver fibrosis defined by liver stiffness measurement (LSM) by transient elastography. ${ }^{14,15}$ Nonetheless this so-called "high-normal" ALT would be defined as abnormal according to the current AASLD criteria and hence those patients were not truly of immune tolerance. Yet in patients with $\mathrm{ALT} \leq 0.5 \mathrm{XULN}, 6.8 \%$ still had advanced fibrosis, the probability would be even high in the subgroup of patients above 35 years old $(15 \%)$. As LSM is least affected if serum ALT is normal, ${ }^{16,17}$ these observations supported what the latest EASL guidelines point out not all patients in the immune-tolerant phase would have minimal fibrosis. ${ }^{6}$

Histology series in Asian-Americans with positive HBeAg, normal ALT (AASLD criteria) and high HBV DNA (mean 7.7 logs copies $/ \mathrm{mL}$ ) demonstrated up to one-quarter of patients had significant fibrosis of $\mathrm{F} 2-3 .^{18} \mathrm{~A}$ prospective cohort involved paired transient elastography examinations at a 3-year interval, liver fibrosis progression happened in 3.1\% among immune-tolerant patients. Liver fibrosis progressed at similar rate (3.3\%) if the immune-active patients received antiviral treatment, but higher risk of such patients did not receive antiviral treatment (13.3\%). ${ }^{19}$ 


\section{Hepatocellular carcinoma}

HBeAg positivity has known to be a risk factor of hepatocellular carcinoma (HCC). ${ }^{20} \mathrm{HCC}$ incidence was 1,169, 324 and 39 per 100,000 person-years among subjects who were positive for both hepatitis B surface antigen ( $\mathrm{HBsAg}$ ) and $\mathrm{HBeAg}$, positive for $\mathrm{HBsAg}$ only, and negative for both, respectively. ${ }^{20}$ However, HBeAg positivity was not equal to immune tolerance as serum ALT was not analyzed; the information of any subsequent immune clearance or HBeAg seroconversion was also not provided. Subsequently a few HCC risk scores also include HBeAg positivity as one of the factors contributing to the scores. For example, REACH-B score identified gender, age, serum ALT level, HBeAg status, and serum HBV DNA level as the factors increasing the HCC risk in non-cirrhotic CHB patients. ${ }^{21}$ But similar to that landmark study, this HBeAg positivity does not necessarily reflecting immune tolerance; instead it reflects immune clearance as patients with elevated ALT and older age are two other risk factors of HCC. Other common HCC risk scores namely CU-HCC score, ${ }^{22,23}$ GAG-HCC score ${ }^{24}$ and LSM-HCC score ${ }^{25}$ do not include HBeAg positivity as a contributing factor, instead they put much more weight and emphasis to the presence of cirrhosis or high LSM. This also indirectly reflect patients in immunetolerant phase are not at increased risk of HCC.

More direct evidence had not been available until very recently proving the above concept could have been wrong. A Korean historical cohort study of $413 \mathrm{HBeAg}$-positive CHB patients with normal ALT (AASLD criteria), high HBV DNA levels ( $\geq 20,000 \mathrm{IU} / \mathrm{mL}$ ) and no evidence of cirrhosis were compared another cohort of 1,497 CHB patients in immune-clearance phase treated with NA. ${ }^{26}$ During the long-term follow up, the 10-year estimated cumulative incidences of HCC was significantly higher in the untreated immune-tolerant patients than the treated patients in immune-clearance phase $(12.7 \%$ vs. $6.1 \% ; P=0.001) .{ }^{26}$ This observation with different conclusion from the above studies may imply either these initially immune-tolerant patients had evolved over time; or the NA treatment reduced the risk of HCC so much that the risk would be even lower than untreated immune-tolerant patients.

\section{TO TREAT OR NOT TO TREAT?}

\section{Virologic response of antiviral treatment for immune-tolerant patients}

A multicenter clinical trial comparing TDF versus TDF and em- tricitabine combination therapy for four years in 162 patients with immune-tolerant CHB revealed low virologic response rates - $0 \%$ to $5 \%$ of $\mathrm{HBeAg}$ seroconversion, and $0 \% \mathrm{HBsAg}$ seroclearance. ${ }^{27}$ A extension follow-up study for another 4 years of a subgroup of 20 Chinese patients from this trial showed a high rate of virologic and clinical relapse after stopping NA in these immune-tolerant patients. ${ }^{28}$ All patients had virologic relapse (HBV DNA $>2,000$ $\mathrm{IU} / \mathrm{mL}$ ) at week 4, $10(50 \%)$ patients had clinical relapse (HBV DNA >2,000 IU/mL and ALT >2xULN); among the 9 untreated patients, 7 remained immune tolerant and 2 had HBeAg seroconversion subsequently. ${ }^{28}$ These observations imply treating patients with immune-tolerant CHB did not alter its natural history much; once the antiviral treatment is stopped, it would be back to square one of high serum HBV DNA.

\section{Recommendations from international guidelines}

Because of the above observations from the landmark clinical trial, the latest AASLD guidelines recommend against antiviral therapy for adults with immune-tolerant $\mathrm{CHB} .{ }^{3}$ The rationale behind is mainly the lack of studies demonstrating antiviral is beneficial in reducing rates of HCC, cirrhosis and liver-related death in patients with immune-tolerant $\mathrm{CHB}$; hence potential harm, including cost, antiviral drug side effects and development of resistance, outweighs its benefits. ${ }^{3}$ AASLD suggests that ALT levels be tested at least every 6 months for adults with immune-tolerant CHB to monitor for potential transition to immune-active or -inactive $\mathrm{CHB}^{3}$

EASL guidelines have a slightly different view on that; delayed HBeAg seroconversion beyond 30 years old is already a treatment indication, as patients with $\mathrm{HBeAg}$-positive chronic HBV infection (i.e. persistently normal ALT and high HBV DNA levels) may consider treatment if they are older than 30 years regardless of the severity of liver histological lesions. ${ }^{6}$ In contrast, such patients younger than 30 years and do not fulfill any of the treatment indications otherwise should be followed at least every 3-6 months.

Antiviral treatment is recommended when HBeAg-positive patients are already out of immune-tolerant phase, namely with high serum ALT $>2 x$ ULN and HBV DNA $>20,000 \mathrm{IU} / \mathrm{mL}$, or serum ALT $>1-2 x \mathrm{ULN}$ and HBV DNA $>2,000 \mathrm{IU} / \mathrm{mL}$ with moderate/severe inflammation or significant liver fibrosis. Certainly, HBeAg-positive patients with compensated liver cirrhosis with detectable HBV DNA (while APASL guidelines set HBV DNA $>2,000 \mathrm{IU} / \mathrm{mL}$ or elevated ALT with detectable HBV DNA), or decompensated liver cirrhosis with detectable HBV DNA. ${ }^{3,4,6}$ 


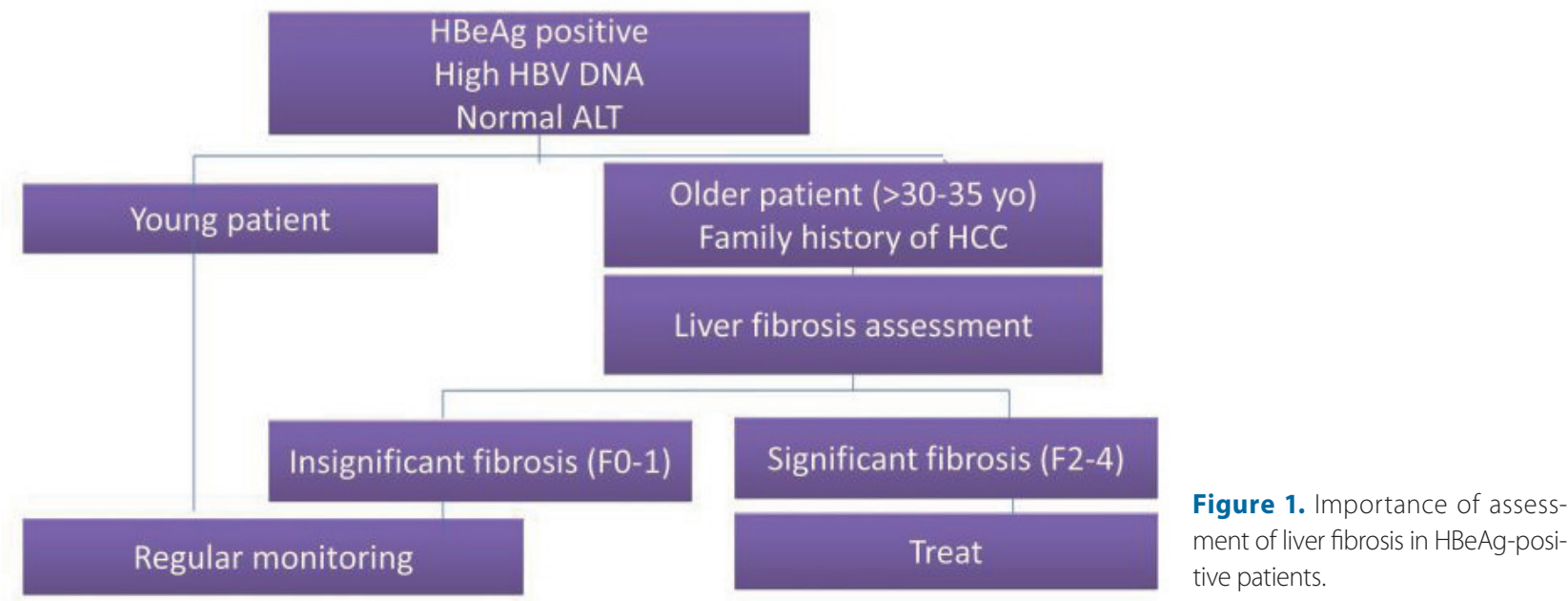

Apart from the conventional serum ALT and HBV DNA levels, EASL guidelines also put the following factors into consideration before starting antiviral treatment for patients at this phase HCC risk, reactivation and transmission of HBV; and extrahepatic manifestation. ${ }^{6}$

\section{Importance of assessment of liver fibrosis in $\mathrm{HBeAg}$ - positive patients (Fig. 1)}

When we are uncertain if an HBeAg-positive patient is really still of immune tolerance, liver biopsy considered to detect advanced liver fibrosis for antiviral therapy, or alternatively with noninvasive assessments such as transient elastography and/or serum tests as first screening tool. ${ }^{29-32}$ APASL guidelines 2015 recommend that noninvasive methods for the estimation of the extent of fibrosis are useful in selecting patients for liver biopsy. Patients with the suggestion of significant fibrosis by noninvasive markers (mean liver stiffness $>8 \mathrm{kPa}$ (by Fibroscan) or aspartate aminotransferase (AST)-to-platelet ratio index (APRI) >1.5) should be considered for liver biopsy. ${ }^{4}$

World Health Organization (WHO) issued her very first specific guidelines for the prevention, care and treatment of persons with CHB in March 2015. ${ }^{33}$ With a global view and coverage (with Africa also included), WHO guidelines provide very practical recommendations with special consideration in resource-limited settings. For example, APRI is recommended as the preferred noninvasive test to assess for the presence of cirrhosis at a cutoff of 2 for adult patients in resource-limited settings. ${ }^{33}$ Other more advanced non-invasive tests namely transient elastography or FibroTest may be preferred in settings that are more resourceful. ${ }^{33}$

\section{Special consideration - Prevention of Maternal-to- Child Transmission of HBV}

One of the recent breakthrough in CHB is the risk and prevention of maternal-to-child transmission (MTCT) of HBV. Multiple observational studies establish the risk of MTCT of HBV in HBeAgpositive mothers despite HBV vaccination to infants, as very often they have very high serum viral load (6 to $9 \log 10 \mathrm{IU} / \mathrm{mL}$ ). ${ }^{34,35}$ This led to the subsequent prospective study of 118 Taiwan HBeAgpositive pregnant women with serum HBV DNA $\geq 7.5 \log 10 \mathrm{IU} /$ $\mathrm{mL} .^{36}$ This was the first study to prove that antiviral treatment with TDF at third trimester to one month post-partum reduce the HBsAg positivity rate of infant compared to no antiviral treatment versus no medication ( $1.54 \%$ vs. $10.71 \% ; P=0.048)$. A multicenter randomized placebo-controlled trial in China provided the level I evidence of the prevention of MTCT of HBV with antiviral treatment at third trimester. ${ }^{37}$ With a slightly lower maternal serum HBV DNA $(<200,000 \mathrm{IU} / \mathrm{mL})$ as the inclusion criterion, the perprotocol analysis of the primary outcome, infants with serum HBV DNA $>20 \mathrm{IU} / \mathrm{mL}$ or $\mathrm{HBsAg}$ positivity at 28 weeks of age was $0 \%$ in the TDF arm and $6.82 \%$ in the placebo arm. ${ }^{37}$

With these new data from two important studies, the latest international guidelines recommend $\mathrm{HBeAg}$-positive mothers with HBV DNA $>10^{6} \mathrm{IU} / \mathrm{mL}^{6}$ or $200,000 \mathrm{IU} / \mathrm{mL}^{3}$ should receive oral antiviral treatment during the last trimester, together with hepatitis B immunoglobulin (HBIG) and HBV vaccination for the newborn. The area of uncertainty now leaves when to stop antiviral treatment. The guidelines recommend to stop immediately or up to 3 months post-partum if the mothers do not meet treatment criteria otherwise. ${ }^{3,6}$ Nonetheless it would be important to closely moni- 
tor the mother as virologic relapse is a rule rather than exception; biochemical flare also occurs but luckily no hepatic decompensation has been observed. ${ }^{36,37}$

\section{HCC RISK AFTER ANTIVIRAL TREATMENT}

Existing literature on $\mathrm{HCC}$ risk in immune-tolerant $\mathrm{CHB}$ is scarce. A recent Korean nationwide real-life study of $484 \mathrm{HBeAg}$-positive CHB patients with normal ALT ( $<40 \mathrm{U} / \mathrm{L})$, high HBV DNA $(>20,000$ $\mathrm{IU} / \mathrm{mL}$ ) and no cirrhosis shed some light on this important yet difficult-to-study topic. Eight-seven of 484 patients received NA; compared to the 397 untreated patients in the control group, NA treatment significantly reduced risk of HCC (with an adjusted hazard ratio of $0.189, P=0.004) .^{38}$ Even though we cannot exclude some of these HBeAg-positive CHB patients might be in the early HBeAg seroclearance phase (as the ALT cutoff was higher than what international guidelines recommend), this important observation, in-line with studies involved patients in other phases of $\mathrm{CHB}^{39}$ that NA treatment reduces risk of $\mathrm{HCC}$.

\section{CONCLUSION}

For HBeAg positive patients with normal ALT and high viral load, liver fibrosis assessment is needed if the patient is older (above 30 or 35 years old) or has family history of HCC. For truly immune-tolerant patients (with no significant fibrosis), the risk of disease progression is generally small. If NA treatment is started, complete viral suppression by NA may be difficult and off-treatment relapse is frequent. Evidence for long-term benefit of treatment is currently evolving. At this moment, regular monitoring is therefore recommended by all key international guidelines.

\section{Authorship Statement}

The author was responsible for the interpretation of data, the drafting, and critical revision of the manuscript for important intellectual content.

\section{Financial support}

This work was supported by the Health and Medical Research Fund from the Food and Health Bureau of the Hong Kong Government granted to Grace Wong (Reference no: 13140651).

\section{Conflicts of Interest}

Grace Wong has served as an advisory committee member for Gilead. She has also served as a speaker for Abbott, Abbvie, Bristol-Myers Squibb, Echosens, Furui, Gilead, Janssen, and Roche.

\section{REFERENCES}

1. Schweitzer A, Horn J, Mikolajczyk RT, Krause G, Ott JJ. Estimations of worldwide prevalence of chronic hepatitis $B$ virus infection: a systematic review of data published between 1965 and 2013. Lancet 2015;386:1546-1555.

2. Trépo C, Chan HL, Lok A. Hepatitis B virus infection. Lancet 2014;384:2053-2063.

3. Terrault NA, Bzowej NH, Chang KM, Hwang JP, Jonas MM, Murad MH. AASLD guidelines for treatment of chronic hepatitis B. Hepatology 2016;63:261-283.

4. Sarin SK, Kumar M, Lau GK, Abbas Z, Chan HL, Chen CJ, et al. Asian-Pacific clinical practice guidelines on the management of hepatitis B: a 2015 update. Hepatol Int 2016;10:1-98.

5. Bertoletti A, Ferrari C. Adaptive immunity in HBV infection. J Hepatol 2016;64(1 Suppl):S71-S83.

6. European Association for the Study of the Liver. EASL 2017 Clinical Practice Guidelines on the management of hepatitis B virus infection. J Hepatol 2017;67:370-398.

7. Mason WS, Gill US, Litwin S, Zhou Y, Peri S, Pop 0, et al. HBV DNA Integration and Clonal Hepatocyte Expansion in Chronic Hepatitis B Patients Considered Immune Tolerant. Gastroenterology 2016;151:986-998. e4.

8. Hong SJ, Park HJ, Chu MA, Choi BS, Choe BH. The Rate of Conversion from Immune-tolerant Phase to Early Immune-clearance Phase in Children with Chronic Hepatitis B Virus Infection. Pediatr Gastroenterol Hepatol Nutr 2014;17:41-46.

9. Song BC, Cho YK, Jwa H, Choi EK, Kim HU, Song HJ, et al. Is it necessary to delay antiviral therapy for 3-6 months to anticipate $\mathrm{HBeAg}$ seroconversion in patients with $\mathrm{HBeAg}$-positive chronic hepatitis B in endemic areas of HBV genotype C? Clin Mol Hepatol 2014;20:355-360.

10. Chan HL, Wong GL, Tse CH, Chim AM, Yiu KK, Chan HY, et al. Hepatitis $B$ virus genotype $C$ is associated with more severe liver fibrosis than genotype B. Clin Gastroenterol Hepatol 2009;7:1361-1366.

11. Kao JH, Chen PJ, Lai MY, Chen DS. Hepatitis B virus genotypes and spontaneous hepatitis B e antigen seroconversion in Taiwanese hepatitis B carriers. J Med Virol 2004;72:363-369.

12. Chu CM, Hung SJ, Lin J, Tai DI, Liaw YF. Natural history of hepatitis $B$ e antigen to antibody seroconversion in patients with normal serum aminotransferase levels. Am J Med 2004;116:829-834. 
13. Andreani T, Serfaty L, Mohand D, Dernaika S, Wendum D, Chazouillères $\mathrm{O}$, et al. Chronic hepatitis B virus carriers in the immunotolerant phase of infection: histologic findings and outcome. Clin Gastroenterol Hepatol 2007;5:636-641.

14. Wong GL. Prediction of fibrosis progression in chronic viral hepatitis. Clin Mol Hepatol 2014;20:228-236.

15. Wong GL, Wong VW, Choi PC, Chan AW, Chim AM, Yiu KK, et al. Clinical factors associated with liver stiffness in hepatitis $B$ e antigen-positive chronic hepatitis B patients. Clin Gastroenterol Hepatol 2009;7:227-233.

16. Chan HL, Wong GL, Choi PC, Chan AW, Chim AM, Yiu KK, et al. Alanine aminotransferase-based algorithms of liver stiffness measurement by transient elastography (Fibroscan) for liver fibrosis in chronic hepatitis B. J Viral Hepat 2009;16:36-44.

17. Wong GL, Espinosa WZ, Wong VW. Personalized management of cirrhosis by non-invasive tests of liver fibrosis. Clin Mol Hepatol 2015;21:200-211

18. Nguyen MH, Garcia RT, Trinh HN, Lam KD, Weiss G, Nguyen HA, et al. Histological disease in Asian-Americans with chronic hepatitis $B$, high hepatitis $B$ virus DNA, and normal alanine aminotransferase levels. Am J Gastroenterol 2009;104:2206-2213.

19. Wong GL, Chan HL, Yu Z, Chan HY, Tse CH, Wong VW. Liver fibrosis progression in chronic hepatitis B patients positive for hepatitis B e antigen: a prospective cohort study with paired transient elastography examination. J Gastroenterol Hepatol 2013;28:1762-1769.

20. Yang HI, Lu SN, Liaw YF, You SL, Sun CA, Wang LY, et al. Hepatitis $B$ e antigen and the risk of hepatocellular carcinoma. N Engl J Med 2002;347:168-174.

21. Yang HI, Yuen MF, Chan HL, Han KH, Chen PJ, Kim DY, et al. Risk estimation for hepatocellular carcinoma in chronic hepatitis B (REACH$\mathrm{B})$ : development and validation of a predictive score. Lancet Oncol 2011:12:568-574

22. Wong GL, Chan HL, Chan HY, Tse PC, Tse YK, Mak CW, et al. Accuracy of risk scores for patients with chronic hepatitis $B$ receiving entecavir treatment. Gastroenterology 2013;144:933-944.

23. Wong VW, Chan SL, Mo F, Chan TC, Loong HH, Wong GL, et al. Clinical scoring system to predict hepatocellular carcinoma in chronic hepatitis B carriers. J Clin Oncol 2010;28:1660-1665.

24. Yuen MF, Tanaka Y, Fong DY, Fung J, Wong DK, Yuen JC, et al. Independent risk factors and predictive score for the development of hepatocellular carcinoma in chronic hepatitis B. J Hepatol 2009;50:80-88.

25. Wong GL, Chan HL, Wong CK, Leung C, Chan CY, Ho PP, et al. Liver stiffness-based optimization of hepatocellular carcinoma risk score in patients with chronic hepatitis B. J Hepatol 2014;60:339-345.

26. Kim GA, Lim YS, Han S, Choi J, Shim JH, Kim KM, et al. High risk of hepatocellular carcinoma and death in patients with immunetolerant-phase chronic hepatitis B. Gut 2017 Oct 21. [Epub ahead of print]

27. Chan HL, Chan CK, Hui AJ, Chan S, Poordad F, Chang TT, et al. Effects of tenofovir disoproxil fumarate in hepatitis $B$ e antigenpositive patients with normal levels of alanine aminotransferase and high levels of hepatitis B virus DNA. Gastroenterology 2014;146:1240-1248.

28. Wong VW, Hui AJ, Wong GL, Chan RS, Chim AM, Lo AO, et al. Fouryear Outcomes After Cessation of Tenofovir in Immune-tolerant Chronic Hepatitis B Patients. J Clin Gastroenterol 2017 Jul 18. [Epub ahead of print]

29. Wong GL. Update of liver fibrosis and steatosis with transient elastography (Fibroscan). Gastroenterol Rep (Oxf) 2013;1:19-26.

30. Wong GL. Transient elastography: Kill two birds with one stone? World J Hepatol 2013;5:264-274.

31. Wong GL, Chan HL, Choi PC, Chan AW, Yu Z, Lai JW, et al. Noninvasive algorithm of enhanced liver fibrosis and liver stiffness measurement with transient elastography for advanced liver fibrosis in chronic hepatitis B. Aliment Pharmacol Ther 2014;39:197-208.

32. Wong GL, Wong VW, Choi PC, Chan AW, Chan HL. Development of a non-invasive algorithm with transient elastography (Fibroscan) and serum test formula for advanced liver fibrosis in chronic hepatitis B. Aliment Pharmacol Ther 2010;31:1095-1103.

33. World Health Organization, Guidelines for the prevention, care and treatment of persons with chronic hepatitis B infection, WHO Website <http://www.who.int/hiv/pub/hepatitis/hepatitis-b-guidelines/ en/>. Accessed 2015.07.03.

34. Liu CP, Zeng $Y L$, Zhou M, Chen LL, Hu R, Wang L, et al. Factors associated with mother-to-child transmission of hepatitis $B$ virus despite immunoprophylaxis. Intern Med 2015;54:711-716.

35. Wen WH, Chang MH, Zhao LL, Ni YH, Hsu HY, Wu JF, et al. Motherto-infant transmission of hepatitis $B$ virus infection: significance of maternal viral load and strategies for intervention. J Hepatol 2013:59:24-30.

36. Chen HL, Lee $\mathrm{CN}$, Chang $\mathrm{CH}$, Ni YH, Shyu MK, Chen SM, et al. Efficacy of maternal tenofovir disoproxil fumarate in interrupting mother-to-infant transmission of hepatitis B virus. Hepatology 2015;62:375-386.

37. Pan CQ, Duan Z, Dai E, Zhang S, Han G, Wang Y, et al. Tenofovir to Prevent Hepatitis B Transmission in Mothers with High Viral Load. N Engl J Med 2016;374:2324-2334.

38. Chang Y, Choe WH, Sinn DH, Lee JH, Ahn SH, Lee H, et al. Nucleos(t) ide Analogue Treatment for Adult Patients with HBeAg-positive Chronic Infection with Genotype C Hepatitis B Virus: A Nationwide Real-life Study. J Infect Dis 2017 Sep 23. [Epub ahead of print]

39. Wong GL, Chan HL, Mak CW, Lee SK, Ip ZM, Lam AT, et al. Entecavir treatment reduces hepatic events and deaths in chronic hepatitis B patients with liver cirrhosis. Hepatology 2013;58:1537-1547. 